\title{
Prevalência da erliquiose monocítica canina e anaplasmose trombocítica em cães suspeitos de hemoparasitose em Cuiabá, Mato Grosso
}

\section{Prevalence of canine monocitic ehrlichiosis and canine thrombocytic anaplasmosis in dogs suspected of hemoparasitosis in Cuiabá Mato Grosso}

\author{
Rute Witter ${ }^{1}$; Sarah Nunes Vecchi²; Thábata dos Anjos Pacheco ${ }^{1}$; \\ Andreia Lima Tomé Melo ${ }^{3}$; Adriana Borsa ${ }^{4}$; Afonso Lodovico Sinkoc ${ }^{4}$; \\ Adriane Jorge Mendonça ${ }^{5}$; Daniel Moura Aguiar ${ }^{6 *}$
}

\begin{abstract}
Resumo
Opresente estudo avaliou a ocorrência da Erliquiose Monocítica Canina eAnaplasmose Trombocitotrópica Canina em 77 cães atendidos no Hospital Veterinário (HOVET) da Universidade Federal de Mato Grosso (UFMT) no ano de 2009, buscando associar à possíveis dados clínicos e hematológicos. Os cães foram avaliados pela amplificação parcial do genes $d s b$ e $16 \mathrm{~S}$ rRNA de Ehrlichia canis e Anaplasma platys e Reação de Imunofluorescência Indireta (RIFI) para E. canis. DNA de E. canis foi detectado em $18(23,3 \%)$ e de $A$. platys em 07 (9,1\%) cães. Cinquenta e quatro (70,1\%) cães foram soropositivos, com títulos variando de 40 a 327.680. Observou-se maior frequência de positivos pela PCR para $E$. canis nos cães com idade até 12 meses, com anemia, linfopenia e trombocitopenia $(\mathrm{P} \leq 0,05)$. Dentre os positivos para $A$. platys, os cães leucopênicos apresentaram tendência à positividade pela $\mathrm{PCR}(\mathrm{P}=0,07)$. Segundo os resultados da RIFI, cães apresentando trombocitopenia e hiperproteinemia foram associados a soropositividade $(\mathrm{P} \leq 0,05)$. Dentre os animais positivos pela $\mathrm{PCR}$ para $E$. canis, a linfoadenopatia e alterações pulmonares foram observada em $15(30,6 \%)$ e $4(57,1 \%)$ cães respectivamente $(\mathrm{P} \leq 0,05)$. Outras alterações não apresentaram associação significativa $(\mathrm{P}>0,05)$ para $E$. canis e A. platys. E. canis foi a única espécie de Ehrlichia detectada em cães atendidos no HOVET no ano de 2009, apresentando alta taxa de infecção em cães jovens e estatisticamente associada a cães anêmicos e trombocitopênicos. Por outro lado, A. platys apresentou baixa ocorrência entre os cães analisados.
\end{abstract}

Palavras-chave: Ehrlichia canis, Anaplasma platys, anemia, trombocitopenia, sorologia, PCR

\begin{abstract}
The present study evaluated Canine Monocytic Ehrlichiosis and Canine Thrombocytic Anaplasmosis in 77 dogs treated at the Veterinary Hospital (HOVET) of the Federal University of Mato Grosso (UFMT) in
\end{abstract}

\footnotetext{
${ }^{1}$ Discentes de Graduação do curso de Medicina Veterinária da Faculdade de Agronomia, Medicina Veterinária e Zootecnia da Universidade Federal de Mato Grosso, UFMT, Cuiabá, MT. E-mail: rutewitter@hotmail.com; thabatanjos@hotmail.com

${ }^{2}$ Médica Veterinária Residente do Hospital Veterinário, UFMT, Cuiabá, MT. E-mail: sarah.vecchi@hotmail.com

${ }^{3}$ Discente de Doutorado do Programa de Pós-Graduação em Ciências Veterinárias, UFMT, Cuiabá, MT. E-mail: andreialtm@ gmail.com

${ }^{4}$ Profs. do Dept ${ }^{\mathrm{o}}$ de Clinica Médica Veterinária da Faculdade de Agronomia, Medicina Veterinária e Zootecnia e do Laboratório de Doenças Parasitárias do Hospital Veterinário, UFMT, Cuiabá, MT. E-mail: driborsa@ufmt.br; alsinkoc@gmail.com

${ }^{5}$ Prof $^{\mathrm{a}}$ do Dept ${ }^{\mathrm{o}}$ de Clinica Médica Veterinária da Faculdade de Agronomia, Medicina Veterinária e Zootecnia e do Laboratório de Patologia Clinica Veterinária do Hospital Veterinário, UFMT, Cuiabá, MT. E-mail: adrianejm@terra.com.br

${ }^{6}$ Prof. do Dept ${ }^{\text {}}$ de Clinica Médica Veterinária da Faculdade de Agronomia, Medicina Veterinária e Zootecnia e do Laboratório de Virologia e Rickettsioses do Hospital Veterinário, UFMT, Cuiabá, MT. E-mail: danmoura@ufmt.br

* Autor para correspondência
} 
2009. An association among clinical and hematological, serological and molecular data was investigated. Dogs were evaluated by partial amplification of dsb and 16S rRNA of Ehrlichia canis and Anaplasma platys and by Indirect Fluorescence Antigen Test (IFAT) for E. canis. DNA of E. canis and A. platys were detected in $18(23.3 \%)$ and $07(9.1 \%)$ dogs respectively. Fifty four $(70.1 \%)$ dogs were positive by IFAT with titers ranging from 40 to 327,680 . There were higher frequencies of $E$. canis positive PCR in dogs less than 12 months old, with anemia, lymphopenia and thrombocytopenia $(\mathrm{P} \leq 0.05)$. Leukopenic dogs presented tendency to be $A$. platys $\mathrm{PCR}$ positive $(\mathrm{P}=0.07)$. Thrombocytopenia and hyperproteinemia of dogs were associated with high anti-E. canis antibody titers $(\mathrm{P} \leq 0.05)$. Lymphadenopathy and pulmonary changes were observed in $15(30.6 \%)$ and $4(57.1 \%)$ E. canis $\mathrm{PCR}$ positive dogs $(\mathrm{P} \leq 0.05)$. No other clinical features were associated between $E$. canis and A. platys infected dogs. E. canis was the only specie of Ehrlichia detected in dogs attended at the HOVET with a higher infection rate in young dogs, and statistically associated with anemic and thrombocytopenic dogs. On the other side, A. platys presented low occurrence among evaluated dogs.

Key words: Ehrlichia canis, Anaplasma platys, anemia, thrombocytopenia, serology, PCR

\section{Introdução}

As hemoparasitoses são enfermidades de grande importância na clinica de animais de companhia, em especial da espécie canina, sendo responsável por elevada casuísta em clínicas e hospitais veterinários. Dentre as diversas causas, a Ehrlichia canis e Anaplasma platys são agentes etiológicos da Erliquiose Monocítica Canina (EMC) e Anaplasmose Trombocítica Canina (ATC) (DUMLER et al., 2001).

E. canis é uma bactéria intracelular obrigatória de células hematopoéticas maduras ou imaturas canina, principalmente da linhagem monocítica como monócitos e linfócitos e nos carrapatos de células de epitélio intestinal e de glândulas salivares (GROVES et al., 1975). Trata-se da principal espécie de Ehrlichia descrita no Brasil, sendo a única espécie do gênero isolada em cães no país (AGUIAR et al., 2013). A doença é considerada endêmica principalmente nas áreas onde abundam populações do carrapato vetor, Rhipicephalus sanguineus (MORAES-FILHO et al., 2011), principal fator de risco para a infecção (TRAPP et al., 2006).

Acredita-se também que $R$. sanguineus seja o principal vetor do $A$. platys (YASBLEY et al., 2008), pois casos de infecção simultânea com $E$. canis são frequentemente relatados (SUKSAWAT et al., 2001). A. platys é uma bactéria gram negativa intracelular obrigatória de plaquetas. Foi descrita pela primeira vez em cães nos Estados Unidos em 1978 (HARVEY; SIMPSON; GASKIN, 1978) e no Brasil o agente vem sendo descrito por exames citológicos e moleculares em cães e gatos (SANTARÉM; LAPOSY; FARIAS, 2005, SANTOS et al., 2009).

Estudos epidemiológicos sobre EMC e ATC no Brasil vem demonstrando que ambos agentes estão presentes em altas prevalência dependendo da região e população canina estudada, variando de $4,8 \%$ no extremo sul do Brasil a $70,9 \%$ na região Centro-Oeste (BULLA et al., 2004; DAGNONE et al., 2003; MELO et al., 2011, SAITO et al., 2008; SANTOS et al., 2009; SILVA et al., 2012; RAMOS et al., 2009; UENO et al., 2009).

A EMC é uma doença multissistêmica, de sintomatologia complexa, que varia na intensidade de acordo com as fases da doença: aguda, assintomática (subclínica) e crônica. Normalmente durante a fase aguda, os cães infectados se recuperam espontaneamente, quando não, entram numa fase assintomática, conhecida por subclínica, permanecendo infectado por longos períodos. Nesta fase, cães que não eliminam o agente do organismo, desenvolvem a fase crônica da doença, caracterizada por supressão medular e sangramentos seguido de morte (HARRUS, WANER, NEER, 2012). A trombocitopenia é o achado hematológico mais comum em pacientes com EMC (HARRUS, 
WANER, NEER, 2012). Neutropenia absoluta pode ocorrer na fase subclínica da doença (CODNER, FARRIS-SMITH, 1986) sendo na fase crônica, caracterizada por pancitopenia devido a hipoplasia e supressão da medula óssea (HARRUS, WANER, NEER, 2012). Na ATC os sinais clínicos incluem febre, apatia e anorexia, e a trombocitopenia cíclica é o principal achado laboratorial ocorrendo em intervalos de 10 a 14 dias (HARRUS, WANER, NEER, 2012).

O diagnóstico laboratorial dessas infecções tem sido rotineiramente realizado pela identificação direta de mórulas de E. canis e A. platys em esfregaços de sangue periférico, associada a exames hematológicos (NAKAGHI et al., 2008). Em anos recentes, com o objetivo de aumentar a sensibilidade e a especificidade do diagnóstico laboratorial, tem sido utilizada a detecção molecular de $E$. canis e $A$. platys, bem como a detecção de anticorpos anti- $E$. canis nos cães suspeitos da doença (AGUIAR et al., 2007).

Diante da constante associação entre cães com baixos valores plaquetários e infecção por $E$. canis e A. platys, o presente estudo objetivou determinar a prevalência molecular e sorológica da EMC e ATC em cães suspeitos de hemoparasitose, atendidos no HOVET da UFMT, buscando associar possíveis dados clínicos e hematológicos para ambas infecções.

\section{Material e Métodos}

Foram avaliadas 77 amostras de sangue encaminhadas ao Laboratório de Parasitologia e Doenças Parasitárias do HOVET-UFMT para a realização de pesquisa de hematozoários. Os cães foram atendidos no Setor de Clínica Médica Veterinária do HOVET da UFMT entre os meses de abril a outubro de 2009. Durante o atendimento, foi requisitada a pesquisa de hematozoários por esfregaço sanguíneo, principalmente devido ao parasitismo por carrapatos no momento da consulta bem como por apresentarem alguns dos sinais clínicos relatados na literatura compatíveis com EMC e ATC tais como: anorexia, hiporexia, apatia, prostração, diarréia, febre, vômito, hepatoesplenomegalia, linfoadenopatia, neuropatias, petéquias e sufusões em mucosas e conjuntivas (HARRUS, WANER, NEER, 2012).

Dos prontuários médicos, obtiveram-se as informações de anamnese, constando dados relativos ao sexo, idade, raça e histórico de infestação por ectoparasitos e a possíveis alterações comportamentais e fisiológicas. Durante o atendimento, foram coletadas amostras de sangue venoso em EDTA de cada cão para exames hematológicos no Laboratório de Patologia Clínica do HOVET, conforme Rizzi, Meinkoth e Clinkenbeard (2000) baseados nos seguintes parâmetros de referência: eritrócitos 5,5-8,5 x 10\% $\mathrm{mm}^{3}$; hemoglobina $12-18 \mathrm{~g} / \mathrm{dl}$; hematócrito 3752\%; VGM 60-77 $\mu^{3}$; CHGM 31-34 g/dl; leucócitos totais $6-18 \times 10^{3} / \mathrm{mm}^{3}$; neutrófilos 3,6-13,8 x 103/ $\mathrm{mm}^{3}$; eosinófilos $0,18-1,8 \times 10^{3} / \mathrm{mm}^{3}$; linfócitos

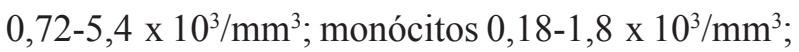
plaquetas $180-400 \times 10^{3} / \mathrm{mm}^{3}$ e proteínas totais $6-8$ $\mathrm{g} / \mathrm{dl}$. Foram considerados anêmicos, leucopênicos e trombocitopênicos os animais que apresentaram valores inferiores aos de referência.

Amostras de sangue total e o plasma sanguíneo foram também utilizados em exames moleculares e sorológicos para o diagnóstico da EMC e ATC no Laboratório de Virologia e Rickettsioses do HOVET. Inicialmente, DNA genômico das amostras foram obtidos por extração de DNA conforme protocolo de Sangioni et al. (2005). A partir do sangue total, foram empregadas três reações de PCR. Inicialmente foi realizada uma PCR de acordo com Aguiar et al. (2007), visando à amplificação de fragmento de 409 pares de base (pb) do gene $d s b$ de Ehrlichia spp., utilizando-se os iniciadores Dsb330 (5'-GAT GAT GTC TGA AGA TAT GAA ACA AAT-3') e Dsb-728 (CTG CTC GTC TAT TTT ACT TCT TAA AGT-3').

Em seguida foi realizada uma reação de 
PCR com intuito de amplificar um fragmento de aproximadamente $480 \mathrm{pb}$ do gene 16S rRNA da família Anaplasmataceae conforme Yasbley et al. (2008) a partir dos oligonucleotídeos ECB (5'-CGTATTACCGCGGCTGCTGGCA-3') e ECC (5'-AGAACGAACGCTGGCGGCAAGCC-3') (1 ${ }^{\mathrm{a}}$ Reação). A partir dos produtos desta reação foram realizados duas nestedPCR. Uma consistindo numa amplificação parcial de $335 \mathrm{pb}$ do gene 16S rRNA de E. canis a partir dos oligonucleotídeos ECAN5 (5'-CAAT TATTTATAGCCTCTGGCTATAGGA-3') e HE3 (5'-TATAGGTACCGTCATTATCTTCCCTAT-3'); e outra para a amplificação de 364 pb de $A$. platys a partir dos oligonucleotídeos PLATYS (5'-TTTGTCGTAGCTTGCTATG-3') e GA1UR (5'-GAGTTTGCCGGGACTTCTTCT-3').

A Reação de Imunofluorescência Indireta (RIFI) foi realizada conforme descrito por Aguiar et al. (2007). O isolado utilizado como antígeno foi a cepa São Paulo de E. canis (AGUIAR; HAGIWARA; LABRUNA, 2008) produzido em cultivo de células DH82 em meio de cultivo Dulbecco's, Modified Eagle's (Sigma Aldrich ${ }^{\circledR}$ ) acrescido de $5 \%$ de soro de bezerro (Bovine Calf Serum - BCS; Hyclone ${ }^{\circledR}$ ) em atmosfera com $5 \%$ de $\mathrm{CO}_{2}$ a $37 \mathrm{C}^{\circ}$. O ponto de corte utilizado para classificar a amostra como positivo foi a diluição inicial de 1:40 em Solução Tampão Fosfatada (PBS pH 7,2), sendo utilizado conjugado de coelho anti-IgG de cão (Sigma Diagnostics, St. Luis, Mo) na diluição de 1:1000. As amostras consideradas positivas foram sucessivamente diluídas na razão dois para obtenção do título final. Em cada lâmina, foram adicionados soros controles sabidamente positivo e negativo.

A avaliação estatística foi realizada com base na associação entre os achados clínicos, exames laboratoriais, PCR e RIFI. Foi considerada a variável dicotômica denominada resultado, que assumiu o valor 1 nos cães caracterizados como positivos nas RIFI e PCRs e 0 se negativo. Para o cálculo da medida de associação foi utilizado o teste do Quiquadrado $\left(\chi^{2}\right)$ e Exato de Fischer quando necessário, ambos com intervalo de confiança de $95 \%$. Para fins de cálculo estatístico, os animais estudados foram segregados nas faixas etárias de 1 a 12 meses, 13 a 24, 25 a 36, e acima de 36 meses. As análises foram realizadas com o auxílio do programa EPIINFO 7.0 para Windows.

\section{Resultados}

Dos 77 cães avaliados, em 18 (23,3\%) foi constatada a presença de DNA compatível com o gênero Ehrlichia pela amplificação parcial do gene $d s b$, sendo todos positivos pela nestedPCR (gene 16S rRNA) específica para E. canis. Cinquenta e quatro cães $(70,1 \%)$ foram reagentes na RIFI apresentando títulos de anticorpos que variaram de 40 a 327.680 . Todos os cães positivos pela PCR foram positivos pela RIFI. Sete $(9,1 \%)$ cães foram positivos pela nestedPCR para A. platys. Quatro cães $(5,2 \%)$ apresentaram-se co-infectados por $A$. platys e E. canis.

Dos animais avaliados 39 (50,6\%) foram fêmeas e $38(49,3 \%)$ foram machos. Dos 18 animais positivos na PCR para E. canis, $13(72,2 \%)$ eram fêmeas e $5(27,7 \%)$ eram machos $(\mathrm{P}>0,05)$. A frequência de animais positivos pela PCR segundo a faixa etária foi maior em animais mais jovens ( 1 a 12 meses) quando comparada aos cães com idade superior $(\mathrm{P} \leq 0,05)$. Pela RIFI, observouse discreto aumento da frequência de reações positivas conforme o aumento da idade, porém sem associação significativa ( $\mathrm{P}>0,05$; Tabela 1$)$. 
Tabela 1. Frequência de cães positivos pela Reação em Cadeia da Polimerase (nestedPCR) e Imunofluorescência Indireta para Ehrlichia canis e Anaplasma platys segundo faixa etária em cães atendidos no Hospital Veterinário da Universidade Federal de Mato Grosso. Cuiabá, MT.

\begin{tabular}{ccccc}
\hline \multirow{2}{*}{ Idade (meses) } & \multirow{2}{*}{$\mathrm{N}$} & \multicolumn{2}{c}{ Ehrlichia canis } & Anaplasma platys \\
\cline { 3 - 5 } & & nestedPCR $^{1}(\%)^{*}$ & RIFI $^{2}(\%)$ & nestedPCR $^{3}$ \\
\hline 1 a 12 & 24 & $8(33,3)^{\mathrm{a}}$ & $16(66,6)^{\mathrm{a}}$ & $4(57,1)^{\mathrm{a}}$ \\
$>12$ a 24 & 13 & $4(30,7)^{\mathrm{a}, \mathrm{b}}$ & $8(61,5)^{\mathrm{a}}$ & 0 \\
$>$ 25 a 36 & 8 & $2(25,0)^{\mathrm{a}, \mathrm{b}}$ & $6(75,0)^{\mathrm{a}}$ & $1(14,3)^{\mathrm{a}}$ \\
> 36 & 32 & $4(12,5)^{\mathrm{b}}$ & $24(75,0)^{\mathrm{a}}$ & $2(28,6)^{\mathrm{a}}$ \\
Total & 77 & $18(23,3)$ & $54(70,2)$ & $7(9,1)^{\mathrm{a}}$ \\
\hline
\end{tabular}

${ }^{1} \mathrm{P}=0,05 ;{ }^{2} \mathrm{P}=0,17 ;{ }^{3} \mathrm{P}=0,30 .{ }^{*}$ Letras diferentes por coluna indica $\mathrm{P}<0,05$.

Fonte: Elaboração dos autores.

Dentre os positivos para $A$. platys, $3(33,3 \%)$ eram fêmeas e $4(66,7 \%)$ eram machos $(\mathrm{P}>0,05)$. Com relação à idade, a maior frequência de cães positivos para $A$. platys foi observada nos cães com até 12 meses de idade $(4 / 24 ; 57,1 \%)$, entretanto sem associação significativa $(\mathrm{P}>0,05)$.

Dentre os animais analisados, dois (2,5\%) apresentaram estruturas compatíveis com mórulas de $E$. canis no esfregaço sanguíneo, e destes apenas um foi confirmado pela PCR. Em 53 (68,9\%) cães foi observada a presença de estruturas compatíveis com mórulas intraplaquetárias em esfregaço sanguíneo. Por outro lado, apenas quatro $(7,5 \%)$ destes foram positivos na PCR para A. platys. Em ambos os casos não foram detectadas associações entre a presença de mórulas de $E$. canis e $A$. platys e positividade nas PCRs $(\mathrm{P}>0,05)$.

Dos 77 cães, $44(57,1 \%)$ estavam parasitados por carrapatos no momento da consulta e dentre estes 15 (34,0\%) foram positivos na PCR para $E$. canis $(\mathrm{P} \leq 0,05)$; três $(9,0 \%)$ cães não parasitados por carrapatos foram positivos. Entre os animais soropositivos pela RIFI, $32(72,7 \%)$ apresentavam carrapatos enquanto $22(66,6 \%)$ não apresentavam ( $\mathrm{P}>0,05)$. Já entre os cães positivos para A. platys, 4 $(10,0 \%)$ apresentavam carrapatos e $3(10,0 \%)$ cães não apresentavam $(\mathrm{P}>0,05)$.

Em relação aos sinais clínicos, foram observados linfoadenopatia em 49 cães $(63,6 \%)$, apatia em 32 (41,5\%), vômito em 22 (28,6\%), anorexia em 20 (26\%), hiporexia em $12(15,6 \%)$ e diarréia em 18 (23,4\%) animais. Apenas cinco (6,5\%) apresentavam algum distúrbio hemorrágico (petéquias e epistaxe em 2 e equimoses em 1 cão). A hepatomegalia foi observada em $3(3,9 \%)$, esplenomegalia em $6(7,8 \%)$, neuropatias em $5(6,5 \%)$, alterações pulmonares em $7(9,1 \%)$ e secreção ocular em 15 (19,5\%) cães. Dentre os animais positivos pela PCR para E. canis, a linfoadenopatia e alterações pulmonares foram observada em 15 (30,6\%) e $4(57,1 \%)$ cães respectivamente $(\mathrm{P} \leq 0,05)$. Outras alterações não apresentaram associação significativa $(\mathrm{P}>0,05)$. Soropositividade pela RIFI foi associada á linfadenopatia e apatia $(\mathrm{P} \leq 0,05)$, observadas em 34 $(69,4 \%)$ e $22(68,8 \%)$ cães respectivamente. Outros sinais não apresentaram associação $(\mathrm{P}>0,05)$ com os resultados da RIFI.

Entre os 7 cães positivos para A. platys observouse os seguintes sinais clínicos: hipertermia em 2 $(28,5 \%)$, hipotermia em $1(14,2 \%)$, linfoadenopatia em $4(57,1 \%)$, apatia em $2(28,5 \%)$, anorexia em 2 $(28,5 \%)$, diarréia em 1 (14,2\%), vômito em $3(42,8 \%)$, esplenomegalia em $1(14,2 \%)$ e alteração pulmonar em $1(14,2 \%)$ cão. Não foi observada associação entre os sinais e a positividade para $A$. platys $(\mathrm{P}>0,05)$.

As alterações hematológicas observadas nos cães segundo a positividade para $E$. canis e $A$. platys encontram-se sumarizados na Tabelas 2 e 3 . Observou-se entre os positivos pela PCR para $E$. canis, decréscimo nos valores referentes aos índices eritrocitários e plaquetários. Entre os cães positivos 
pela RIFI, destacaram-se as alterações plaquetárias e de proteínas séricas. Não foram observadas associações entre os achados laboratoriais e cães positivos para A. platys. Cães co-infectados por E. canis e $A$. platys não apresentaram quaisquer associação com sintomatologia clínica e resultados laboratoriais.

Tabela 2. Associação entre os resultados dos exames hematológicos, Reação em Cadeia da Polimerase (nestedPCR) e Reação de Imunofluorescência Indireta (RIFI) para Ehrlichia canis em cães atendidos no Hospital Veterinário da Universidade Federal de Mato Grosso. Cuiabá, MT.

\begin{tabular}{|c|c|c|c|c|c|}
\hline \multirow{2}{*}{ Exames hematológicos } & \multicolumn{5}{|c|}{ Cães } \\
\hline & $n$ & nestedPCR (\%) & $P$ & RIFI (\%) & $P$ \\
\hline \multicolumn{6}{|l|}{ VG } \\
\hline$>55$ & 1 & $0(0)$ & \multirow{3}{*}{0,001} & $1(100,0)$ & \multirow{3}{*}{0,08} \\
\hline $37-55$ & 41 & $3(7,3)$ & & $25(61,0)$ & \\
\hline$<37$ & 35 & $15(42,9)$ & & $28(80,0)$ & \\
\hline \multicolumn{6}{|l|}{ CHGM } \\
\hline$>36,0$ & 2 & $2(100,0)$ & \multirow{3}{*}{0,05} & $2(100,0)$ & \multirow{3}{*}{1,00} \\
\hline $32,0-36,0$ & 41 & $9(22,2)$ & & $30(73,2)$ & \\
\hline$<32,0$ & 34 & $4(20,6)$ & & $22(64,7)$ & \\
\hline \multicolumn{6}{|l|}{ VGM } \\
\hline$>77$ & 0 & $0(0)$ & \multirow{3}{*}{1,00} & $0(0)$ & \multirow{3}{*}{0,29} \\
\hline $60-77$ & 76 & $18(23,7)$ & & $54(71,1)$ & \\
\hline$<60$ & 1 & $0(0)$ & & $0(0)$ & \\
\hline \multicolumn{6}{|l|}{ Hemácias } \\
\hline$>5.500$ & 0 & $0(0)$ & \multirow{3}{*}{0,001} & $0(0)$ & \multirow{3}{*}{0,17} \\
\hline $5.500-8.500$ & 48 & $5(10,4)$ & & $31(64,6)$ & \\
\hline$<5.500$ & 29 & $13(44,8)$ & & $23(79,3)$ & \\
\hline \multicolumn{6}{|l|}{ Hemoglobina } \\
\hline$<12$ & 1 & $0(0)$ & \multirow{3}{*}{0,001} & $1(100,0)$ & \multirow{3}{*}{0,07} \\
\hline $12-18$ & 34 & $3(8,8)$ & & $20(58,8)$ & \\
\hline$>18$ & 42 & $15(35,7)$ & & $33(78,6)$ & \\
\hline \multicolumn{6}{|l|}{ Leucócitos } \\
\hline$<5.500$ & 15 & $4(26,7)$ & \multirow{3}{*}{0,73} & $8(53,3)$ & \multirow{3}{*}{0,20} \\
\hline $5.500-17.000$ & 47 & $11(23,4)$ & & $33(70,2)$ & \\
\hline$>17.000$ & 15 & $3(20,0)$ & & $13(86,7)$ & \\
\hline \multicolumn{6}{|l|}{ Neutrófilos } \\
\hline$<3.600$ & 12 & $3(25,0)$ & & $6(50,0)$ & \\
\hline $3.600-13.000$ & 49 & $12(24,5)$ & 1,00 & $35(71,4)$ & 0,36 \\
\hline$>13.000$ & 16 & $3(1,8)$ & & $13(81,3)$ & \\
\hline Linfócitos & & & & & \\
\hline$<700$ & 18 & $7(38,9)$ & & $14(77,8)$ & \\
\hline $700-5.100$ & 58 & $11(19,0)$ & 0,07 & $39(67,2)$ & 1,00 \\
\hline$>5.100$ & 1 & $0(0)$ & & $1(100,0)$ & \\
\hline Monócitos & & & & & \\
\hline$<200$ & 4 & $0(0)$ & & $1(25,0)$ & \\
\hline $200-1.700$ & 67 & $16(23,9)$ & 0,62 & $47(70,1)$ & 0,17 \\
\hline$>1.700$ & 6 & $2(33,3)$ & & $6(100,0)$ & \\
\hline Eosinófilos & & & & & \\
\hline$<100$ & 23 & $6(26,1)$ & & $15(65,2)$ & \\
\hline $100-1.700$ & 51 & $12(23,5)$ & 0,71 & $36(70,6)$ & 0,24 \\
\hline$>1.700$ & 3 & $0(0)$ & & $3(100,0)$ & \\
\hline Plaquetas & & & & & \\
\hline$>400.000$ & 6 & $1(16,7)$ & & $4(66,7)$ & \\
\hline $180.000-400.000$ & 30 & $3(10,0)$ & 0,01 & $17(56,7)$ & \\
\hline$<180.000$ & 41 & $14(34,1)$ & & $33(80,5)$ & 0,03 \\
\hline Proteínas & & & & & \\
\hline$<6$ & 16 & $5(31,3)$ & & $12(75,0)$ & \\
\hline $6-8$ & 44 & $9(20,5)$ & 0,40 & $25(56,8)$ & 0,001 \\
\hline$>8$ & 17 & $4(23,5)$ & & $17(100,0)$ & \\
\hline
\end{tabular}

Valores de referência: hematócrito (VG) 37-52\%; CHGM 31-34 g/dl; VGM 60-77 $\mu^{3}$; hemácias 5,5-8,5 x 10\% $/ \mathrm{mm}^{3}$; hemoglobina

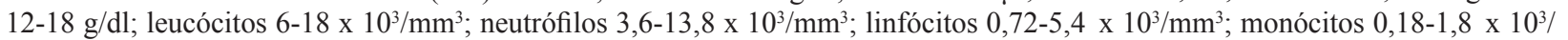
$\mathrm{mm}^{3}$; eosinófilos $0,18-1,8 \times 10^{3} / \mathrm{mm}^{3}$; plaquetas $180-400 \times 10^{3} / \mathrm{mm}^{3}$ e proteínas totais $6-8 \mathrm{~g} / \mathrm{dl}$.

Fonte: Elaboração dos autores. 
Tabela 3. Associação entre os resultados dos exames hematológicos e Reação em Cadeia da Polimerase (nestedPCR) para Anaplasma platys em cães atendidos no Hospital Veterinário da Universidade Federal de Mato Grosso. Cuiabá, MT.

\begin{tabular}{|c|c|c|c|}
\hline \multirow{2}{*}{ Exames hematológicos } & \multicolumn{3}{|c|}{$n P C R$} \\
\hline & $n$ & nestedPCR (\%) & $P$ \\
\hline \multicolumn{4}{|c|}{ 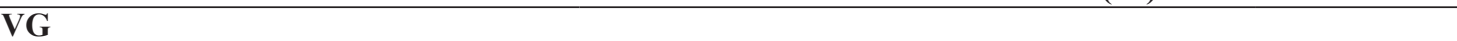 } \\
\hline$>55$ & 2 & $0(0)$ & \multirow{3}{*}{0,52} \\
\hline $37-55$ & 46 & $4(8,7)$ & \\
\hline$<37$ & 42 & $3(7,1)$ & \\
\hline \multicolumn{4}{|l|}{ CHGM } \\
\hline$>36,0$ & 2 & $0(0)$ & \multirow{3}{*}{0,60} \\
\hline $32,0-36,0$ & 50 & $4(8,0)$ & \\
\hline$<32,0$ & 36 & $3(8,3)$ & \\
\hline \multicolumn{4}{|l|}{ VGM } \\
\hline$>77$ & 0 & $0(0)$ & \multirow{3}{*}{0,92} \\
\hline $60-77$ & 87 & $7(8,0)$ & \\
\hline$<60$ & 1 & $0(0)$ & \\
\hline \multicolumn{4}{|l|}{ Hemácias } \\
\hline$>5.500$ & 1 & $0(0)$ & \multirow{3}{*}{0,55} \\
\hline $5.500-8.500$ & 53 & $4(7,5)$ & \\
\hline$<5.500$ & 34 & $3(8,8)$ & \\
\hline \multicolumn{4}{|l|}{ Hemoglobina } \\
\hline$>12$ & 2 & $0(0)$ & \multirow{3}{*}{0,37} \\
\hline $12-18$ & 39 & $4(10,3)$ & \\
\hline$<12$ & 47 & $3(6,4)$ & \\
\hline \multicolumn{4}{|l|}{ Leucócitos } \\
\hline$<5.500$ & 17 & $3(17,6)$ & \multirow{3}{*}{0,12} \\
\hline $5.500-17.000$ & 56 & $4(7,1)$ & \\
\hline$>17.000$ & 17 & $0(0)$ & \\
\hline \multicolumn{4}{|l|}{ Segmentados } \\
\hline$<3.600$ & 14 & $3(21,4)$ & \multirow{3}{*}{0,07} \\
\hline $3.600-13.000$ & 56 & $4(7,1)$ & \\
\hline$>13.000$ & 18 & $0(0)$ & \\
\hline \multicolumn{4}{|l|}{ Linfócitos } \\
\hline$<700$ & 21 & $1(4,8)$ & \multirow{3}{*}{0,07} \\
\hline $700-5.100$ & 66 & $5(7,6)$ & \\
\hline$>5.100$ & 1 & $1(100,0)$ & \\
\hline \multicolumn{4}{|l|}{ Monócitos } \\
\hline$<200$ & 5 & $0(0)$ & \multirow{3}{*}{0,40} \\
\hline $200-1.700$ & 77 & $6(7,8)$ & \\
\hline$>1.700$ & 6 & $1(16,7)$ & \\
\hline \multicolumn{4}{|l|}{ Eosinófilos } \\
\hline$<100$ & 26 & $2(7,7)$ & \multirow{3}{*}{0,55} \\
\hline $100-1.700$ & 58 & $5(8,6)$ & \\
\hline$>1.700$ & 4 & $0(0)$ & \\
\hline Plaquetas & & & \\
\hline$>400.000$ & 6 & $0(0)$ & \\
\hline $180.000-400.000$ & 36 & $2(5,6)$ & 0,26 \\
\hline$<180.000$ & 46 & $5(10,9)$ & \\
\hline Proteínas & & & \\
\hline$<6$ & 20 & $3(15,0)$ & \\
\hline $6-8$ & 51 & $3(5,9)$ & 0,18 \\
\hline$>8$ & 19 & $1(5,3)$ & \\
\hline
\end{tabular}

Valores de referência: hematócrito (VG) 37-52\%; CHGM 31-34 g/dl; VGM 60-77 $\mu^{3}$; hemácias 5,5-8,5 x 106/ $\mathrm{mm}^{3}$; hemoglobina

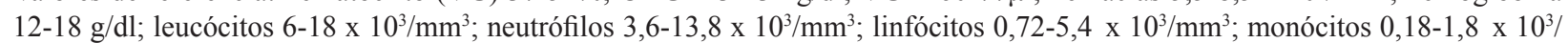
$\mathrm{mm}^{3}$; eosinófilos $0,18-1,8 \times 10^{3} / \mathrm{mm}^{3}$; plaquetas $180-400 \times 10^{3} / \mathrm{mm}^{3}$ e proteínas totais $6-8 \mathrm{~g} / \mathrm{dl}$.

Fonte: Elaboração dos autores. 


\section{Discussão}

O presente estudo objetivou determinar a prevalência dos agentes $E$. canis e A. platys entre cães suspeitos de hemoparasitose atendidos no HOVET-UFMT no ano de 2009. Os resultados moleculares e sorológicos diagnosticaram 18 $(23,3 \%)$ e $54(70,1 \%)$ cães positivos para E. canis respectivamente e $7(9,1 \%)$ para $A$. platys. Quando comparados a resultados de outros hospitais veterinários do Brasil, observamos variações, ora inferior ora semelhante dos valores, dependendo do teste diagnóstico realizado. Para E. canis, as prevalências baseadas na PCR variam de $21,7 \%$ em Londrina, PR a 57\% em Recife, PE (DAGNONE et al., 2003, RAMOS et al., 2009). Valores de prevalência baseadas na RIFI apresentam-se acima dos encontrado pela PCR, concordando com os resultados do presente trabalho. Nakaghi et al. (2008) em Jaboticabal, SP e Azevedo et al. (2011) na Paraíba, pela RIFI relataram $63,3 \%$ e $72,5 \%$ de positividade respectivamente. A sorologia tem um papel importante nas fases subclínica e crônica da doença, sendo frequente a detecção de altos índices de soropositivos, visto a enzootia observada em regiões tropicais e subtropicais, principalmente onde ocorrem infestações por $R$. sanguineus (VIEIRA et al., 2011). Todos os cães positivos pela PCR confirmaram-se positivos pela RIFI sugerindo infecção ativa por E. canis. Entende-se que os outros 36 cães soropositivos, mas negativos pela PCR foram previamente infectados pelo agente e estes podem ou não evoluir para a fase crônica da doença (HARRUS, WANER, 2011).

Dentre os fatores de risco relatados na literatura consultada, o parasitismo por carrapatos $R$. sanguineus (TRAPP et al., 2006) foi associado a positividade pela PCR para E. canis. Entretanto, nem sempre esta associação tem sido observada por outros autores (UENO et al., 2009; SOUSA et al., 2010). No presente trabalho, não observamos associação entre a presença de $R$. sanguineus e anticorpos anti-E. canis. Como a presença de anticorpos reflete infecções passadas, não é necessário que o cão esteja parasitado por carrapatos para ser soropositivo.

Deve-se salientar no presente estudo que as associações entre sinais clínicos e hematologia e o diagnóstico molecular de $A$. platys devem ser vistas com cautela dado a baixa prevalência para este agente, pois é provável que isto impediu a significância estatística na maioria das análises. De acordo com nossos resultados, $9,1 \%$ dos cães foram positivos para $A$. platys. Resultados próximos dos relatados por Santos et al. (2009) na região de Ribeirão Preto, onde 14,9\% dos cães atendidos em Hospitais Veterinários também foram positivos pela mesma técnica para $A$. platys. Resultados mais expressivos foram observados por Silva et al. (2012) em 19,4\% dos cães de Jataizinho, PR e por Ramos et al. (2009) que observou frequência de $55 \%$ para $A$. platys em cães atendidos em Hospital Veterinário de Pernambuco, todos com sintomas clínicos de hemoparasitose. Tudo indica que a infecção por $A$. platys não é a principal causa de hemoparasitose nos cães atendidos no Hospital Veterinário da UFMT de Cuiabá, MT. Dos cães parasitados por carrapatos, quatro foram positivo para $A$. platys, entretanto a diferença entre cães não infectados não foi confirmado pela analise estatística. São poucas as informações sobre a transmissão de $A$. platys, mesmo sabendo da importância do $R$. sanguineus. É provável que devido ao caráter crônico da infecção por $A$. platys, a ausência do carrapato não é indicativo de que o cão não fora infectado anteriormente. Silva et al. (2012) em Ribeirão Preto também não observaram associação entre presença de carrapatos com a presença de $A$. platys.

Dos 77 cães avaliados, em dois (4,2\%) e 53 $(68,9 \%)$ cães, respectivamente, foram constatados a presença de estruturas compatíveis com mórulas de $E$. canis e $A$. platys nos esfregaços sanguíneos. Entretanto, apenas um cão com mórulas de E. canis foi positivo e quatro foram positivos na PCR para A. platys. Estruturas semelhantes à corpúsculos de inclusão em células sanguíneas muitas vezes 
estão relacionados à ativação celular em processos inflamatórios e podem ser confundidos com mórulas de E. canis. De acordo com Mylonakis et al. (2003) outras inclusões intracitoplasmáticas, incluindo grânulos azurófilos e material proveniente de fagocitose podem ser confundidos com mórulas, o que pode gerar resultados falso-positivos, reduzindo a especificidade da citologia. Este resultado também foi observado por Ueno et al. (2009), em hospital veterinário de Botucatu, SP que também observaram mórulas compatíveis com E. canis no exame citológico mas resultando negativo na PCR. Adicionalmente, a utilização do protocolo de PCR baseado na amplificação parcial do gene $d s b$ descarta a participação de outra espécie de Ehrlichia no processo infeccioso, uma vez que todas foram confirmadas como E. canis pela nestedPCR. Estes resultados ressaltam que, apesar dos baixos custos e rapidez dos resultados, o exame citológico tem apresentado baixa sensibilidade e especificidade quando comparado a exames de PCR, ressaltando a importância dos testes moleculares no diagnóstico das hemoparasitoses.

A detecção de E. canis na corrente sanguínea pela PCR, sugere fase aguda ou fase assintomática da doença, pois nesta última podem ocorrer ciclos de parasitemia do agente. A faixa etária mais acometida (1-12 meses) com 33,3\% de frequência ressalta essa hipótese, sugerindo que esses animais jovens, possivelmente não tenham atingido ainda a fase crônica da doença. Por outro lado, os soropositivos, mas PCR negativos se enquadram nos cães cronicamente infectados, onde E. canis é ausente da corrente sanguínea a despeito da sua presença na medula óssea, linfonodos e baço (HARRUS, WANER, 2011). Ueno et al. (2009) também evidenciaram maior frequência da infecção em animais jovens com até 12 meses de idade. Com relação a infecção por $A$. platys, a maior frequência de cães positivos também foi observada na faixa etária dos animais com até 12 meses de idade, entretanto não foi observada associação desta infecção com a faixa etária. Com relação ao sexo, não foram observadas associações entre os cães positivos para E. canis e A. platys, concordando com as observações de Sousa et al. (2010) e Silva et al. (2012) que também não observaram predileção relacionada à essa variável.

Em se tratando de sinais clínicos, as alterações pulmonares (presença de estertores, quadros dispneicos, tosse, espirros e secreção nasal) foram as que apresentaram associação com a positividade para E. canis. Assim como os resultados de Ueno et al. (2009), esses achados clínicos não são característicos da EMC, onde mais comumente se observa apatia, linfoadenopatia, febre e emagrecimento (HARRUS, WANER, NEER, 2012). Por outro lado, este resultado pode ser reflexo de imunossupressão sabidamente presente nos cães com EMC. Não foram observados sinais clínicos associados à infecção por $A$. platys. A infecção por A. platys não possui sinais patognomônicos, pois os sinais clínicos são frequentemente associados à outras doenças concomitantes, como a própria EMC (HARRUS, WANER, NEER, 2012). Devido a ausência de sinais clínicos patognomônicos, o diagnóstico da infecção por $A$. platys é de extrema relevância no diferencial das hemoparasitoses.

Os valores plaquetários e eritrocitários apresentaram-se associados com a infecção por $E$. canis na PCR. O achado de trombocitopenia em cães infectados por E. canis está em concordância com outros estudos no Brasil (DAGNONE et al., 2003; BULLA et al., 2004; NAKAGHI et al., 2008; UENO et al., 2009). Os resultados confirmam a trombocitopenia como a alteração hematológica mais comum nas infecções por $E$. canis. Por outro lado esse achado não é o único, uma vez que a infecção por E. canis pode ocasionar supressão difusa da medula óssea, induzindo trombocitopenia, anemia e leucopenia (BUHLES, HUXSOLL, RISTIC, 1974). Valores eritrocitários abaixo do limite inferior também foram descritos por Harrus et al. (1996), Castro et al. (2004) e Hasegawa et al. (2005). Mesmo diante da ausência de associação com sinais clínicos, a apatia e a 
presença de mucosas pálidas apresentaram-se frequentes entre os animais positivos para E. canis e podem ser consequência dos baixos valores eritrocitários.

Nenhuma das variáveis hematológicas apresentou associação com a positividade para A. platys. Entretanto, os cães com leucopenia e neutropenia apresentaram tendência à positividade na PCR ( $\mathrm{P}=0,12$ e 0,07 respectivamente). Não houve associação entre a positividade para $A$. platys e trombocitopenia, pois dos cães com essa alteração somente cinco (10,9\%) foram positivos, diferindo dos resultados relatado por Silva et al. (2012) que observaram associação do agente com a trombocitopenia.

O aumento de proteínas plasmáticas totais observada em animais positivos na RIFI para $E$. canis pode ser resultado da hiperglobulinemia e hipergammaglobulinemia, como também observado por Shipov et al. (2008). A hipoalbuminemia, hiperglobulinemia e hipergammaglobulinemia são anormalidades comuns em cães com EMC, pois ocorre em doenças com estimulação antigênica prolongada e sugere uma aberrante e exagerada resposta imune e humoral com eficácia inadequada (HARRUS et al., 1996).

Concluímos que a E. canis é responsável por transtornos hematológicos como anemia e trombocitopenia e acomete frequentemente os animais mais jovens no HOVET, em Cuiabá, MT. O diagnóstico baseado em alterações clínicas e hematológicas, bem como na presença de mórulas de E. canis em esfregaços sanguíneos não são suficientes para o diagnóstico da EMC, já que os sinais da doença são inespecíficos e o exame citológico muitas vezes não condiz com real infecção. Dentre as diversas causas de hemoparasitose, a infecção por $A$. platys não foi relevante no período estudado. Ressaltamos a importância dos testes moleculares e sorológicos no diagnóstico da EMC e ATC, e estes devem ser incluídos na rotina médica veterinária.

\section{Agradecimentos}

À Fundação de Amparo a Pesquisa do Estado de Mato Grosso (FAPEMAT) pelo auxilio financeiro concedido a D.M. Aguiar para o desenvolvimento desta pesquisa e pelas bolsas de S.N. Vecchi e T.A. Pacheco. A Coordenação de Aperfeiçoamento de Pessoal de Nível Superior (CAPES) pela bolsa de A.L.T. Melo. Ao Conselho Nacional de Desenvolvimento Científico e Tecnológico (CNPQ) pelas bolsas de R. Witter e D.M. Aguiar.

\section{Comitê de Ética e Biossegurança}

O presente trabalho foi avaliado pelo Comitê de Bioética e/ou de Biossegurança da UFMT sendo aprovado sob o protocolo número 23108.051170/10-0.

\section{Referências}

AGUIAR, D. M.; HAGIWARA, M. K.; LABRUNA, M. $B$. In vitro isolation and molecular characterization of an Ehrlichia canis strain from São Paulo, Brazil. Brazilian Journal of Microbiology, São Paulo, v. 39, n. 3, p. 489493, 2008.

AGUIAR, D. M.; SAITO, T. B.; HAGIWARA, M. K.; LABRUNA, M. B. Diagnóstico sorológico de erliquiose canina com antígeno brasileiro de Ehrlichia canis. Ciência Rural, Santa Maria, v. 37, n. 3, p. 796-802, 2007.

AGUIAR, D. M.; ZHANG, X.; MELO, A. L. T.; PACHECO, T. A.; MENESES, A. M. C.; ZANUTTO, M. S.; HORTA, M. C.; SANTARÉM, V. A.; CAMARGO, L. M. A.; MCBRIDE, J. W.; LABRUNA, M. B. Genetic diversity of Ehrlichia canis in Brazil. Veterinary Microbiology, Barcelona, v. 164, n. 3-4, p. 315-321, 2013.

AZEVEDO, S. S.; AGUIAR, D. M.; AQUINO, S. F.; ORLANDELli, R. C.; FERNANDES, A. R. F.; UCHÔA, I. C. P. Soroprevalência e fatores de risco asociados à soropositividade para Ehrlichia canis em cães do semiárido da Paraíba. Brazilian Journal of Veterinary Research and Animal Science, São Paulo, v. 48, n. 1, p. 14-18, 2011.

BUHLES, W. C.; HUXSOLL, D. L.; RISTIC, M. Tropical canine pancytopenia: clinical, hematologic, and serologic response of dogs to Ehrlichia canis infection, 
tetracycline therapy, and challenge inoculation. Journal of Infectious Diseases, Cary, v. 130, n. 4, p. 357-367, 1974.

BULLA, C.; TAKAHIRA, R. K.; ARAUJO JUNIOR, J. P.; TRINCA, L. A.; LOPES, R. S.; WIEDMEYER, C. E. The relationship between the degree of thrombocytopenia and infection with Ehrlichia canis in an endemic area. Veterinary Research, Ottawa, v. 35, n. 1, p. 141-146, 2004.

CASTRO, M. B.; MACHADO, R. Z.; AQUINO, L. P. C. T.; ALESSI, A. C.; COSTA, M. T. Experimental acute canine monocytic ehrliquiosis: clinicopathological and immunopathological findings. Veterinary Parasitology, Amsterdam, v. 119, n. 1, p. 73-86, 2004.

CODNER, E. C.; FARRIS-SMITH, L. Characterization of the subclinical phase of ehrlichiosis in dogs. Journal of the American Veterinary Medical Association, New York, v. 189, n. 1, p. 47-50, 1986.

DAGNONE, A. S.; AUTRAN, H. S. M.; VIDOTTO, M. C.; JOJIMA, F. S.; VIDOTTO, O. Ehrlichiosis in anemic, thrombocytopenic, or tick-infested dogs from a hospital population in south Brazil. Veterinary Parasitology, Amsterdam, v. 117, n. 4, p. 285-290, 2003.

DUMLER, J. S.; BARBET, A. F.; BEKKER, C. P. J.; DASCH, G. A.; PALMER, G. H.; RAY, S. C.; RIKIHISA, Y.; RURANGIRWA, F. R. Reorganization of genera in the families Rickettsiaceae and Anaplasmataceae in the order Rickettsiales: unification of some species of Ehrlichia with Anaplasma, Cowdria with Ehrlichia and Ehrlichia with Neorickettsia, descriptions of six new species combinations and designation of Ehrlichia equi and HGE agent as subjective synonyms of Ehrlichia phagocytophila. International Journal of Systematic and Evolutionary Microbiology, London, v. 51, n. 6, p. 21452165. 2001.

GROVES, M. G.; DENNIS, G. L.; AMYX, H. L.; HUXSOLL D. L. Transmission of Ehrlichia canis to dogs by ticks (Rhipicephalus sanguineus). American Journal of Veterinary Research, Chicago, v. 36, n. 7, p. 937-940, 1975.

HARRUS, S.; WANER, T. Diagnosis of canine monocytotropic ehrlichiosis (Ehrlichia canis): an overview. The Veterinary Journal, London, v. 187, n. 3, p. 292-296, 2011.

HARRUS, S.; WANER, T.; AVIDAR, Y.; BOGIN. E.; PEH, H.; BARK, H. Serum protein alterations in canine ehrlichiosis. Veterinary Parasitology, Amsterdam, v. 66, n. 3-4, p. 241-249, 1996.

HARRUS, S.; WANER, T.; NEER, T. M. Ehrlichia and anaplasma infections. In: GREENE, C. E. Infectious diseases of the dog and cat. Philadelphia: Elsevier B.V. Saunders Company, 2012. p. 227-238.

HARVEY, J. W.; SIMPSON, C. F.; GASKIN, J. M. J. Cyclic thrombocytopenia induced by a Rickettsia-like agent in dogs. The journal of Infectious Diseases, Cary, v. 137, n. 2, p. 182-188, 1978.

HASEGAWA, M. Y.; KOHAYAGAWA, A.; BRANDÃO, L. P.; MORGULIS, M. S.; HAGIWARA, M. K. Evaluation of neutrophil oxidative metabolism in canine monocytic ehrlichiosis. Veterinary Clinical Pathology, v. 34, n. 3, p. 213-217, 2005.

MELO, A. T. L.; MARTINS, T. F.; HORTA, M. C.; MORAES-FILHO, J.; PACHECO, R. C.; LABRUNA, M. B.; AGUIAR, D. M. Seroprevalence and risk factors to Ehrlichia spp. and Rickettsia spp. in dogs from the Pantanal Region of Mato Grosso State, Brazil. Ticks and Tick borne Disease, Berlin, v. 2, n. 4, p. 213-218, 2011.

MORAES-FILHO, J.; MARCILI, A.; NIERI-BASTOS, F. A.; RICHTZENHAIN, L. J.; LABRUNA, M. B. Genetic analysis of ticks belonging to the Rhipicephalus sanguineus group in Latin America. Acta Tropica, Canada, v. 117, n. 1, p. 51-55, 2011.

MYLONAKIS, M. E.; KOUTINAS, A. F.; BILLINIS, C.; LEONTIDES, L. S.; KONTOS, V.; PAPADOPOULOS, O.; RALLIS, T.; FYTIANOU, A. Evaluation of cytology in the diagnosis of acute canine monocyticehrlichiosis (Ehrlichia canis): a comparison between five methods. Veterinary Microbiology, Barcelona, v. 91, n. 2-3, p. 197204, 2003.

NAKAGHI, A. C. H.; MACHADO, R. Z.; COSTA, M. T.; ANDRÉ, M. R.; BALDANI, C. D. Canine ehrlichiosis: clinical, hematological, serological and molecular aspects. Ciência Rural, Santa Maria, v. 38, n. 3, p.766-770, 2008.

RAMOS, C. A. N.; RAMOS, R. A. N.; ARAÚJO, F. R.; GUEDES, D. S.; SOUZA JUNIOR, I. I.; ONO, T. M.; VIEIRA, A. S.; PIMENTEL, D. S.; ROSAS, E. O.; FAUSTINO, M. A.; ALVES, L. C. Comparação de nested-PCR com o diagnóstico direto na detecção de Ehrlichia canis e Anaplasma platys em cães. Revista Brasileira de Parasitologia Veterinária, Jaboticabal, v. 18, p. 58-62, 2009. Suplemento 1.

RIZZI, T. E.; MEINKOTH, J. H.; CLINKENBEARD, K. Normal hematology of the dog. In: FELDMAN, B. F.; ZINKL, J. G.; JAIN, N. C. Schalm's veterinary hematology. 5. ed. Philadelphia: Lippincott Williams e Wilkins, 2000.

SAITO, T. B.; CUNHA-FILHO, N. A.; PACHECO, R. C.; FERREIRA, F.; PAPPEN, F. G.; FARIAS, N. A.; LARSSON, C. E.; LABRUNA, M. B. Canine Infection 
by Rickettsiae and Ehrlichiae in Southern Brazil. The American Journal of Tropical Medicine and Hygiene, Cleveland, v. 79, n. 1, p. 102-108, 2008.

SANGIONI, L. A.; HORTA, M. C.; VIANNA, M. C.; GENNARI, S. M.; SOARES, R. M.; GALVAO, M. A. Rickettsial infection in animals and Brazilian Spotted Fever endemicity. Emerging Infectious Diseases, Atlanta, v. 11, n. 2, p. 265-270, 2005.

SANTARÉM, V. A.; LAPOSY, C. B.; FARIAS, M. R. Inclusões plaquetárias semelhantes a Anaplasma platys (Ehrlichia platys) em gato. Colloquium Agrariae, Presidente Prudente, v. 1, n. 2, p. 60-66, 2005.

SANTOS, F.; COPPEDE, J. S.; PEREIRA, A. L.; OLIVEIRA, L. P.; ROBERTO, P. G.; BENEDETTI, R. B.; ZUCOLOTO, L. B.; LUCAS, F.; SOBREIRA, L.; MARINS, M. Molecular evaluation of the incidence of Ehrlichia canis, Anaplasma platys and Babesia spp. in dogs from Ribeirão Preto, Brazil. The Veterinary Journal, London, v. 179, n. 1, p. 145-148, 2009.

SHIPOV, A.; KLEMENT, E.; REUVENI-TAGER, L.; WANER, T.; HARRUS, S. Prognostic indicators for canine monocytic ehrlichiosis. Veterinary Parasitology, Amsterdam, v. 153, n. 1-2, p. 131-138, 2008.

SILVA, G. C.; BENITEZ ADO, N.; GIROTTO, A.; TARODA, A.; VIDOTTO, M. C.; GARCIA, J. L.; FREITAS, J. C.; ARLINGTON, S. H.; VIDOTTO, O. Occurrence of Ehrlichia canis and Anaplasma platys in household dogs from northern Parana. Revista Brasileira de Parasitologia Veterinária, Jaboticabal, v. 21, n. 4, p. 379-385, 2012.
SOUSA, V. R. F.; ALMEIDA, A. B. P. F.; BARROS, L. A.; SALES, K. G.; JUSTINO, C. H. S.; DALCIN, L.; BOMFIM, T. C. B. Avaliação clínica e molecular de cães com erliquiose. Ciência Rural, Santa Maria, v. 40, n. 6, p. 1309-1313, 2010.

SUKSAWAT, J.; PITULLE, C.; ARRAGAALVARADO, C.; MADRIGAL, K.; HANCOCK, S. I.; BREITSCHWERDT, E. B. Coinfection with three Ehrlichia species in dogs from Thailand and Venezuela with emphasis on consideration of $16 \mathrm{~S}$ ribosomal DNA secondary structure. The Journal of Clinical Microbiology, Washington DC, v. 39, n. 1, p. 90-93, 2001.

TRAPP, S. M.; DAGNONE, A. S.; VIDOTTO, O.; FREIRE, R. L.; AMUDE, A. M.; MORAIS, H. S. Seroepidemiology of canine babesiosis and ehrlichiosis in a Hospital population. Veterinary Parasitology, Amsterdam, v. 140, n. 3-4, p. 223-230, 2006.

UENO, T. E.; AGUIAR, D. M.; PACHECO, R. C.; RICHTZENHAIN, L. J.; RIBEIRO, M. G.; PAES, A. C.; MEGID, J.; LABRUNA, M. B. Ehrlichia canis em cães atendidos em hospital veterinário de Botucatu, Estado de São Paulo, Brasil. Revista Brasileira de Parasitologia Veterinária, Jaboticabal, v. 18, n. 3, p. 57-61, 2009.

VIEIRA, R. F. C.; BIONDO, A. W. A.; GUIMARÃES, A. M. S.; SANTOS, A. P. dos; SANTOS, R. P. dos; DUTRA, L. H.; DINIZ, P. P.; MORAIS, H. A.de; MESSICK, J. B.; LABRUNA, M. B.; VIDOTTO, O. Ehrlichiosis in Brazil. Revista Brasileira de Parasitologia Veterinária, Jaboticabal, v. 20, n. 1, p. 1-12, 2011. 